\title{
Phase Transition Behavior of Nylon-66, Nylon-48, and Blends
}

\author{
Gongzheng Zhang, Takafumi WATANABE, Hirohisa YoshIDA, ${ }^{\dagger}$ and Tadashi KAWAI \\ Graduate School of Engineering, Tokyo Metropolitan University \\ 1-1 Minamiousawa, Hachiouji, Tokyo 192-0397, Japan
}

(Received September 12, 2002; Accepted October 30, 2002)

\begin{abstract}
Phase transitions, including $\alpha-\beta$ phase transition and melting, of nylon- 66 , nylon- 48 and blends were measured by simultaneous DSC-XRD and DSC-FT-IR. The molecular mechanism of $\alpha-\beta$ transition and melting of nylon66 and blends were estimated from DSC-XRD and DSC-FT-IR. On the broad endothermic peak between 100 and $200^{\circ} \mathrm{C}$, spacing of (010/110) of $\alpha$-form expanded from $0.36 \mathrm{~nm}$ to $0.40 \mathrm{~nm}$, and spacing of (100) of $\alpha$-form changed from $0.44 \mathrm{~nm}$ to $0.41 \mathrm{~nm}$, then (100) of $\beta$-form appeared. The triclinic ab plane changed to the rhombohodral ab plane from 100 to $20{ }^{\circ} \mathrm{C}$. The slide of hydrogen bonded sheet induced transition to the hexagonal $\beta$-form. Double melting peaks on DSC heating curve were due to the melting of two types of $\beta$-form consisted with weak and strong hydrogen bonded molecules. Composition dependence of $\alpha-\beta$ transition temperatures obtained by DSC-XRD and DSC-FT-IR showed good agreement with that of the equilibrium melting temperature. Nylon-66 and nylon-48 are thus in a miscible state at the molecular level.

KEY WORDS Phase Transition / Simultaneous Differential Scanning Calorimetry X-Ray Diffraction (DSC-XRD) / Simultaneous Differential Scanning Calorimetry Fourier Transform Infrared Spectrometry (DSC-FT-IR) / Nylon-66 / Nylon-48 / Polymer Blend /
\end{abstract}

Nylon-66 is an important semicrystalline polymer. Nylon-66 shows solid-state transition called as the Brill transition, ${ }^{1}$ and multiple melting ${ }^{2-5}$ on heating from the room temperature to $280^{\circ} \mathrm{C}$. At the Brill transition, the triclinic $\alpha$-form changes to a pseudohexagonal $\beta$ form. The temperature of the Brill transition has been reported variously from 100 to $240^{\circ} \mathrm{C}$, which appears sensitive to crystallization, annealing and deformation of the sample. ${ }^{2}$ Many studies on the Brill transition for nylon have been carried out by XRD, NMR, FT-IR, and DSC. ${ }^{2-9}$ Multiple melting is commonly observed in the nylon-66 sample crystallized from solution in methanol. ${ }^{5}$ Several mechanisms of multiple melting are proposed such as independent melting of polymorphism of nylon-66, melt and re-crystallization of unstable crystallites and reorganization of amorphous parts. The mechanism of transitions is not fully understood owing to the complexity in multiple transitions.

Thermal analysis, especially DSC is convenient to observe phase transition, however, DSC gives only total thermodynamic information of samples. Other measurements are necessary to obtain structural information. We have reported that the simultaneous DSC-FTIR and DSC-XRD methods give not only thermal information but also conformational and structural information on real time of transitions such as crystallization, melting and solid-state transition. ${ }^{10-12}$ Applications of the simultaneous DSC-FT-IR and DSC-XRD were reported to analyze the mechanism of $\alpha-\gamma$ transition of

${ }^{\dagger}$ To whom correspondence should be addressed.
PVDF. ${ }^{13,14}$ In the present work simultaneous DSC-FTIR and DSC-XRD methods were used to analyze the molecular mechanism of phase transitions of nylon-66, nylon-48 and blends during heating.

\section{EXPERIMENTAL}

Nylon-66 (Scientific Polymer Products) and nylon48 , prepared using the interface polymerization of chloro octanedioyl and butanediamine, were used in this study. The relative viscosity of nylon-66 and nylon-48 is $\eta_{\text {rel }}=1.79$ and 1.90 respectively (measured at $25^{\circ} \mathrm{C}$ in $m$-cresol). Nylon-66 and nylon-48 were dissolved in $m$-cresol at room temperature. Blend content of nylon-66 $\left(\phi_{\text {Nylon-66 }}\right)$ was $0-1.0$ in weight fraction $\left(\phi_{\text {Nylon-66 }}=0.8\right.$ indicates blend of composition nylon-48/nylon- $66=0.2 / 0.8$ ). After precipitating from methanol and drying at $100^{\circ} \mathrm{C}$ in a vacuum over for $48 \mathrm{~h}$, blend samples were pressed at $280^{\circ} \mathrm{C}$ and quenched into ice water. The obtained blend films were dried under vacuum at room temperature for $48 \mathrm{~h}$.

Thermal analysis of nylon-66 and blends was carried out with SEIKO Differential Scanning Calorimeter (DSC200) connected to the Seiko thermal analysis system SCC $5200 \mathrm{H}$. DSC samples were heated from $100^{\circ} \mathrm{C}$ to $280^{\circ} \mathrm{C}$ and maintained at that temperature for $5 \mathrm{~min}$, and cooled to $150^{\circ} \mathrm{C}$ at $5^{\circ} \mathrm{C} \mathrm{min}{ }^{-1}$ under nitrogen gas flow. The samples were quenched to room temperature and heated again from $50{ }^{\circ} \mathrm{C}$ to $280^{\circ} \mathrm{C}$ at $5^{\circ} \mathrm{C} \min ^{-1}$. 
Simultaneous $\mathrm{DSC}^{15}$ was set on a Mac Science M06XCE XRD equipped with a CCD detector and incident monochrometor operating at $50 \mathrm{kV}$ and $24 \mathrm{~mA}$, the X-Ray wavelength was $0.15405 \mathrm{~nm}$. Simultaneous DSC scanning condition was same to DSC measurement. The sample sandwiched with two thin aluminum foils and cramped in an aluminum sample vessel was used for DSC-XRD measurement. Sample weight used was about $5.0 \mathrm{mg}$. Time and angular resolutions of XRD profile were $30 \mathrm{sec}$ and $0.01^{\circ}$, respectively.

Simultaneous DSC ${ }^{15}$ was set on JASCO FT-IR 620 equipped with a MCT detector. DSC scanning rate was $5{ }^{\circ} \mathrm{C} \mathrm{min}^{-1}$. Wavenumber and time resolutions of FTIR measurement were $2 \mathrm{~cm}^{-1}$ and $15 \mathrm{sec}$, respectively. The samples were prepared from solvent casting on a glass plate at $100^{\circ} \mathrm{C}$ in a desiccator. The obtained films were dried under vacuum at room temperature for $48 \mathrm{~h}$. The sample film sandwiched with thin $\mathrm{KBr}$ dishes was used for DSC-FT-IR measurement. The samples were heated from 50 to $280^{\circ} \mathrm{C}$. During heating, DSC exotherm and FT-IR spectra were recorded.

\section{RESULTS AND DISCUSSION}

DSC heating curves at a rate of $5{ }^{\circ} \mathrm{C} \mathrm{min}^{-1}$ for nylon66, nylon- 48 and blend are shown in Figure 1. A broad endothermic peak between $100-200^{\circ} \mathrm{C}$ and double melting peaks were observed on DSC curves of nylon-66 and nylon-48. The broad endothermic peak is associated with the $\alpha-\beta$ transition, Brill transition. Melting peaks occur at 254.1 and $263.4^{\circ} \mathrm{C}$ for nylon66 , which is very similar to the result reported previously. $^{2}$ For nylon-48 shown in Figure 1, the broad endotherm peak associated with the $\alpha-\beta$ transition shows

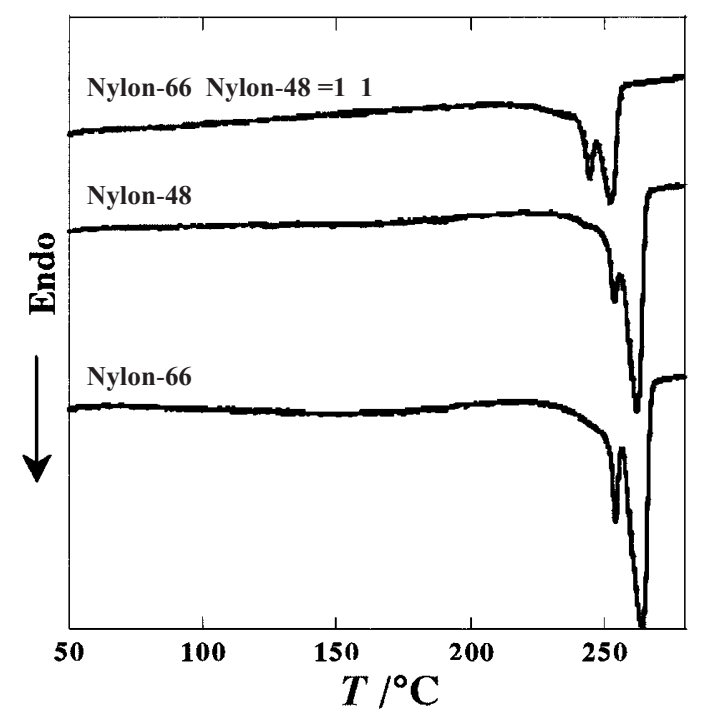

Figure 1. DSC heating curves for nylon-66, nylon-48, and their blend at $5^{\circ} \mathrm{C} \mathrm{min}^{-1}$. also in $100-200^{\circ} \mathrm{C}$, two melting peaks occur at 253.7 and $262.3^{\circ} \mathrm{C}$. Nylon- 66 and nylon- 48 show the similar temperature of the $\alpha-\beta$ transition temperature and the melting, because nylon- 66 and nylon- 48 are isomeric compounds.

For the blend shown in Figure 1, a broad endothermic peak around $100^{\circ} \mathrm{C}$ and two melting peaks at 244.4 and $252.1{ }^{\circ} \mathrm{C}$, lower than those of nylon-66 or nylon48. Nylon-66 and nylon-48 are miscible from analysis of crystallization dynamics. ${ }^{16}$ Nylon-66 and nylon-48 have the same number of amide groups in the repeating unit, and similar distance between hydrogen bonding along the main chain. The temperature range of the $\alpha-\beta$ transition for the blend lower than that pure nylon-66 or nylon-48 indicated interactions between nylon- 66 and nylon-48 to effect the phase transition. Starkweather ${ }^{2}$ reported effects of heating rate on the temperature of the endothermic peaks of melting and $\alpha-\beta$ transition. A double melting peak was observed only at heating rates up to $20^{\circ} \mathrm{C} \mathrm{min}^{-1}$, and the temperature of the second peak was independent of heating rate. ${ }^{5}$

From simultaneous DSC-FT-IR, the conformational and thermal changes were monitored in real time of the phase transitions on heating. Figure 2 shows FT-IR profiles (Figure 2a) and absorbance changes at $934 \mathrm{~cm}^{-1}$ compared with DSC curve (Figure $2 b$ ) for nylon-66 observed on heating at $5{ }^{\circ} \mathrm{C} \mathrm{min}^{-1}$ obtained by simultaneous DSC-FT-IR. The IR band at $934 \mathrm{~cm}^{-1}$ is a crystalline band of nylon-66, associated with the $\alpha$ form. ${ }^{6}$ This band is sharp and strong in the solutioncrystallized and melt-crystallized samples and absent in the melt. ${ }^{6}$ The band at $934 \mathrm{~cm}^{-1}$ was used as an index of $\alpha$-form crystallinity in this study. For nylon-66 (Figure 2), absorbance at $934 \mathrm{~cm}^{-1}$ started to decrease at heating from $100^{\circ} \mathrm{C}$ until $200^{\circ} \mathrm{C}$. The decrease of absorbance at $934 \mathrm{~cm}^{-1}$ corresponded to the $\alpha-\beta$ transition. From the DSC curve, the band at $934 \mathrm{~cm}^{-1}$ disappeared completely before melting. This result indicates that double melting peaks showed in the DSC curve are not related with the $\alpha$-form conformation. Vasanthan and Murthy ${ }^{7}$ reported that when a sample of nylon-66 is heated from room temperature to the melting temperature $\left(260^{\circ} \mathrm{C}\right)$, sharp crystalline bands (e.g., $935 \mathrm{~cm}^{-1}$ ) become weaker and broader and disappear in the melt. From DSC-FT-IR, $\alpha$-form crystalline bands disappeared completely before melting.

Figure 3 shows absorbance changes at 3300 and $1643 \mathrm{~cm}^{-1}$ overlapping on a DSC curve for nylon-66 obtained by simultaneous DSC-FT-IR at $5^{\circ} \mathrm{C} \mathrm{min}^{-1}$. Bands at 3300 and $1643 \mathrm{~cm}^{-1}$ were assigned to the hydrogen bonded $\mathrm{OH}$ stretching and hydrogen bonded $\mathrm{CO}$ stretching, respectively. Absorbance at both bands decreased at the $\alpha-\beta$ transition, suggesting that rearrange- 


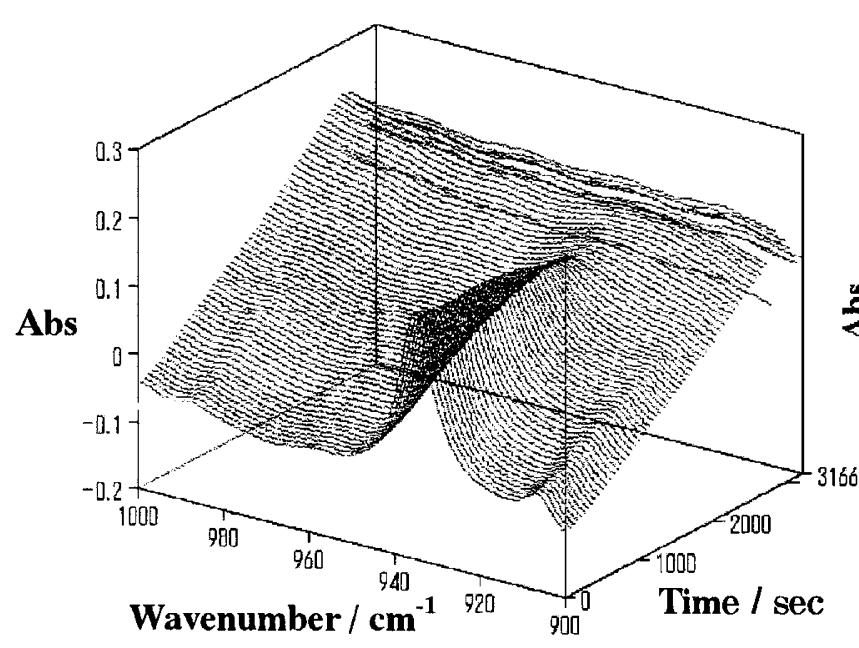

(a)

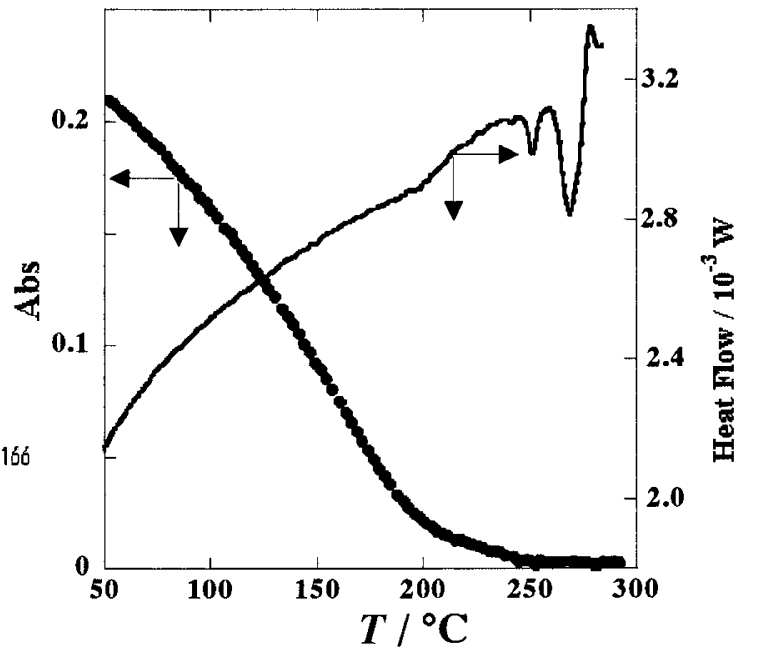

(b)

Figure 2. FT-IR spectral (a) and absorbance changes at $934 \mathrm{~cm}^{-1}$ overlapping with DSC heating curve (b) for nylon-66 observed by the simultaneous DSC-FT-IR method on heating at $5^{\circ} \mathrm{C} \mathrm{min}^{-1}$.

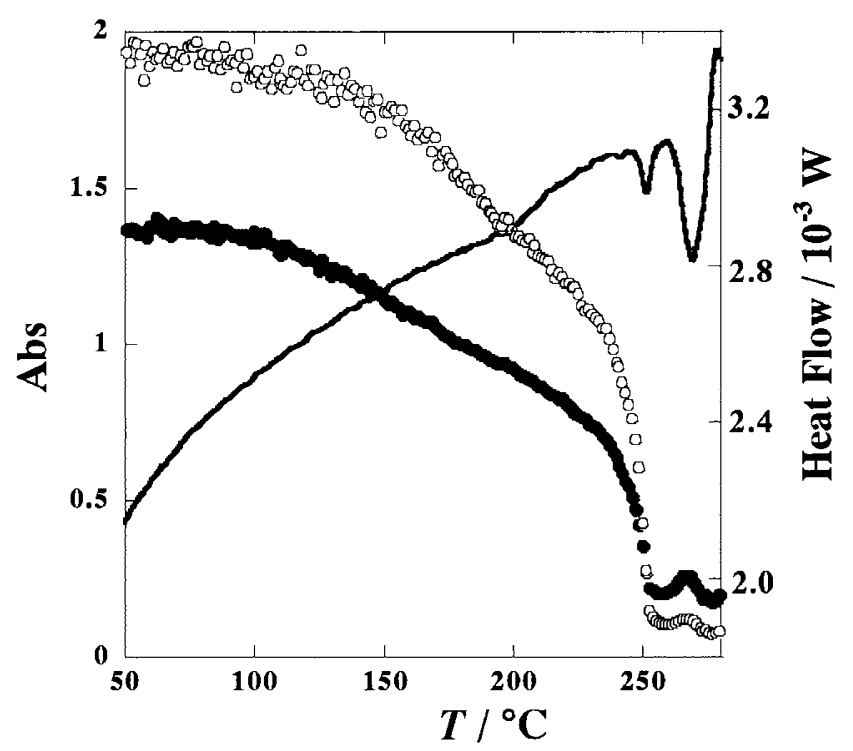

Figure 3. Changes of absorbance at 3300 (black circle) and $1643 \mathrm{~cm}^{-1}$ (white circle) and DSC curve for nylon-66 by the simultaneous DSC-FT-IR method on heating at $5{ }^{\circ} \mathrm{C} \mathrm{min}^{-1}$.

ment of hydrogen bonding occurs following the $\alpha-\beta$ transition. At melting, absorbance at both bands decreased steeply at the lower melting peak. Absorbance at both bands increased between the double melting peaks. This result indicates that the higher melting peak is due to the melting of crystal consisted with stronger hydrogen bonded molecules.

Simultaneous DSC-XRD data of nylon-48 obtained by heating from 50 to $280^{\circ} \mathrm{C}$ at $5^{\circ} \mathrm{C} \mathrm{min}-1$ are shown in Figure 4a (XRD profiles) and Figure 4b (XRD analysis data and DSC). At lower temperature, two crystalline reflections at $2 \theta=20.3^{\circ}$ and $24.8^{\circ}$, corresponding to $(100)$ and $(010,110)$ spacings of $\alpha$-form for nylon- $66^{17}$ were observed for nylon-48. Two reflection peaks shifted in opposite directions with temper- ature and overlapped above $200{ }^{\circ} \mathrm{C}$. A single diffraction peak $\left(2 \theta=21.5^{\circ}\right)$ appears over $200^{\circ} \mathrm{C}$, corresponding to the (100) spacing of $\beta$-form of nylon- $66 .{ }^{17} \mathrm{Hy}-$ drogen bonding dominates the crystal structure of nylon, and hydrogen-bonded sheets are the main feature of the nylon structure and two strong reflections (100) and (010) are came from the intermolecular distance in hydrogen-bonded sheets and the distance between hydrogen-bonded sheets, respectively. ${ }^{17}$ The $\mathrm{d}$ spacing at $2 \theta=20.3^{\circ}$ and $24.8^{\circ}$ for nylon- 48 are almost same as those of nylon-66, therefore, (010) and (100) are due to the intersheet distance between hydrogen bonded sheets and projected interchain distance within the sheet, respectively. In the $\alpha$-form structure, the hydrogen bonds exist like a step in hydrogen-bonded sheets, while the hydrogen bonds exist in alternate in the $\beta$-form. ${ }^{8}$ On the $\alpha-\beta$ transition, (100) plan shrank from 0.44 to $0.40 \mathrm{~nm}$ and (010) plan expanded from 0.36 to $0.41 \mathrm{~nm}$ in triclinic $\alpha$-form. Finally, the triclinic cell took on a rhombic shape at around $200{ }^{\circ} \mathrm{C}$. At $210^{\circ} \mathrm{C}$, the hydrogen bonded sheet slipped alternatively and $\alpha-\beta$ transition occurred. During the broad endothermic peak, the expansion of (010) plane and shrinkage of (100) plane occurred gradually, and (010) and (100) planes of triclinic cell changed to (100) hexagonal cell with sliding of hydrogen bonded sheets.

$T_{\alpha-\beta}$ in Figure 4 is the $\alpha-\beta$ temperature at which $\alpha$-phase transforms completely to $\beta$-phase. At $T_{\mathrm{m}}<$ $T<T_{\alpha-\beta}$, the $\beta$-phase is stable. At the melting point, the (100) reflection peak of the $\beta$-phase disappears. The closed triangles in Figure 4 above $263.2{ }^{\circ} \mathrm{C}$ correspond to amorphous halo of nylon-48. The double melting peaks on the DSC curve were only related to the $\beta$-phase. Simultaneous DSC-XRD plots of nylon66 and nylon- $66 /$ nylon- 48 blends were in the same way 


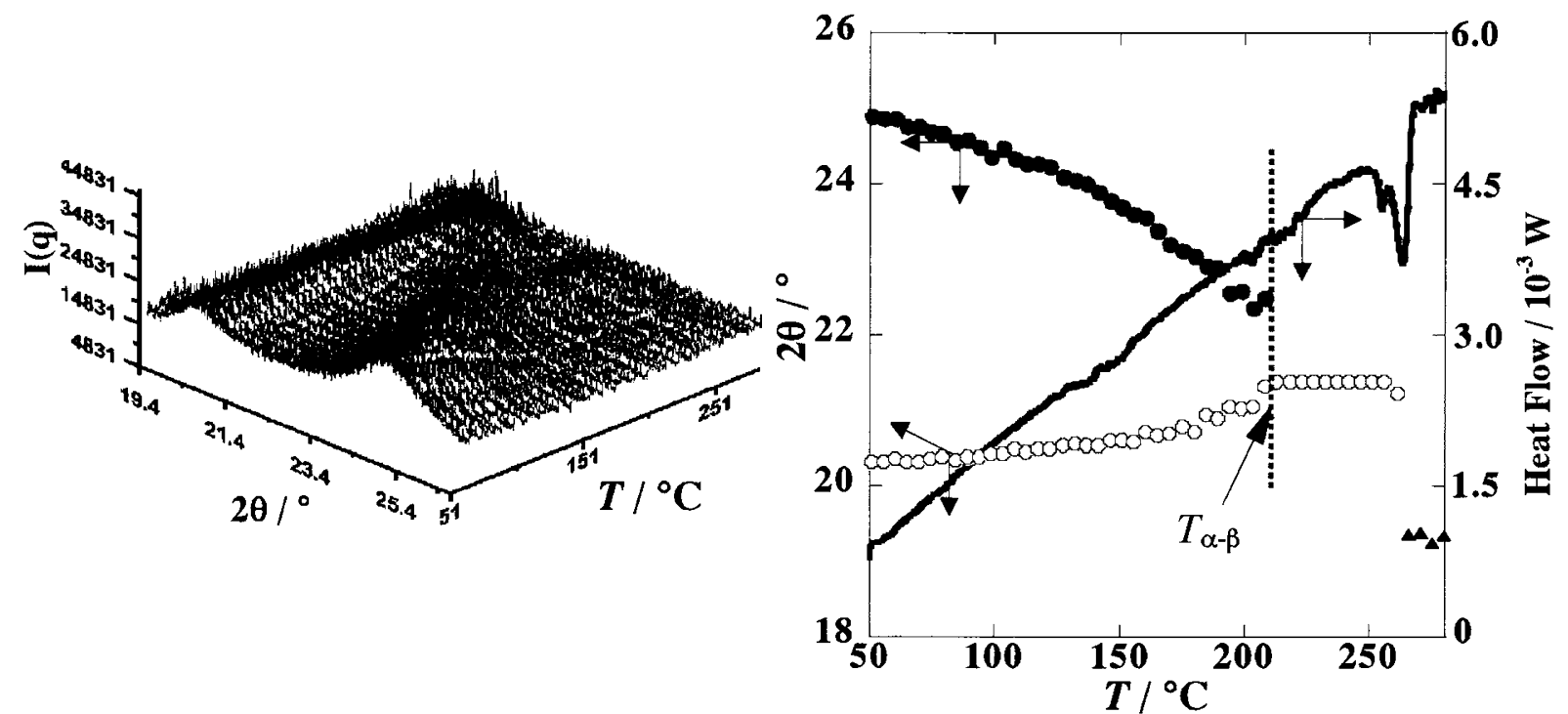

(a)

(b)

Figure 4. XRD profile change (a) and diffraction peak changes overlapped with DSC heating curve (b) for nylon- 48 observed by the simultaneous DSC-XRD method on heating at $5{ }^{\circ} \mathrm{C} \mathrm{min}^{-1}$.

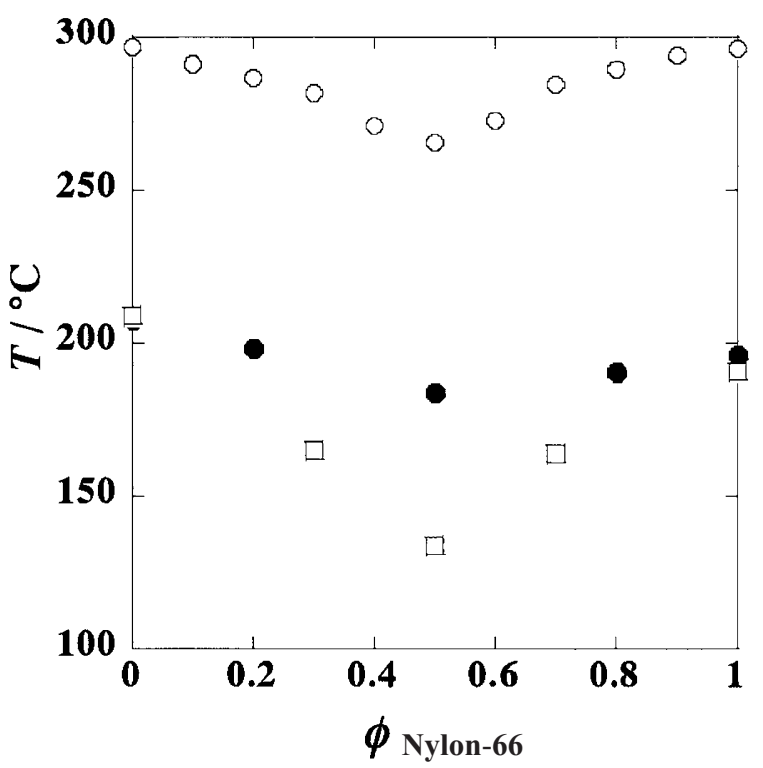

Figure 5. $\phi_{\text {Nylon-66 }}$ dependency of $T_{\mathrm{m}}{ }^{0}(\bigcirc)$ and $T_{\alpha-\beta}$ obtained by DSC-WAXD ( $\square$ ) and DSC-FT-IR ( $)$ for the nylon-66/nylon48 blends

as nylon-48 in Figure 4.

Figure 5 shows $\phi_{\text {Nylon-66 }}$ dependency of the equilibrium melting temperature $\left(T_{\mathrm{m}}{ }^{0}\right)^{16}$ and $\alpha-\beta$ transition temperature $\left(T_{\alpha-\beta}\right)$ obtained by DSC-XRD and DSC-FT-IR for nylon-66/nylon-48 blends. In semicrystalline polymer blends, melting temperature depression is well explained by the interaction parameter $\left(\chi_{12}\right)$ using Flory-Huggins equation ${ }^{18,19}$ or the Nishi-Wang equation..$^{20}$ The $\chi_{12}$ value of nylon-66/nylon-48 blends obtained in the range of $\phi_{\text {Nylon-66 }}=0.5-1.0$ was -2.1 by Flory-Huggins equation. Negative $\chi_{12}$ indicated the blends were miscible in the melt state. As shown in Figure $5, \phi_{\text {Nylon-66 }}$ dependency of $T_{\mathrm{m}}{ }^{0}$ indicated the eutectic compound type phase diagram. Nylon66 and nylon-48 produced the eutectic compound at $\phi_{\text {Nylon-66 }}=0.5$. Not only $T_{\mathrm{m}}{ }^{0}$ but also $T_{\alpha-\beta}$ showed strong $\phi_{\text {Nylon-66 }}$ dependency. $T_{\alpha-\beta}$ evaluated from DSCXRD was clearly determined by the absence of (100) and (010) diffractions of $\alpha$-form. However, $T_{\alpha-\beta}$ was evaluated as the intersection of absorbance change at $934 \mathrm{~cm}^{-1}$ from the DSC-FT-IR results shown in Figure 2. The difference between $T_{\alpha-\beta}$ evaluated by DSCXRD and DSC-FT-IR was a result of the sensitivity difference of monitoring species. As the $\alpha-\beta$ transition occurred at the solid state, $\phi_{\text {Nylon-66 }}$ dependency of $T_{\alpha-\beta}$ suggested that nylon-66 and nylon-48 were miscible in molecular level.

\section{CONCLUSION}

The mechanism of phase transitions, including $\alpha-\beta$ phase transition and melting, of nylon-66, nylon- 48 and blends were analyzed by simultaneous DSC-XRD and DSC-FT-IR methods. On the broad endothermic peak between 100 and $200{ }^{\circ} \mathrm{C}$, the spacing of $(010 / 110)$ of $\alpha$-form expanded from $0.36 \mathrm{~nm}$ to $0.40 \mathrm{~nm}$, and the spacing of (100) of $\alpha$-form changed from $0.44 \mathrm{~nm}$ to $0.41 \mathrm{~nm}$, and (100) of $\beta$-form appeared. The triclinic $\alpha$-form changed to the rhombohodral $\alpha$-form from 100 to $200^{\circ} \mathrm{C}$, and the slide of hydrogen-bonded sheet induced the transition to the hexagonal $\beta$-form. The double melting peaks on DSC heating curve were due to the melting of two types of $\beta$-form containing irregular and regular hydrogen bonded molecules. Both the equilibrium melting temperature and the $\alpha-\beta$ transition temperature showed the strong blend composition depen- 
dency. These results suggest that nylon-66 and nylon48 are the miscible system at the molecular level.

\section{REFERENCES}

1. R. Brill, J. Prakt. Chem., 161, 49 (1942).

2. H. W. Starkweather and G. A. Jones, J. Polym. Sci., Polym. Phys. Ed., 19, 467 (1981).

3. G. H. Hatfield, J. H. Glans, and W. B. Hammond, Macromolecules, 23, 1654 (1990).

4. H. J. Biangardi, J. Macromol. Sci., Phys., B29, 139 (1990).

5. H. W. Starkweather, J. R. Paulzoller, and G. A. Jones, J. Polym. Sci., Polym. Phys. Ed., 22, 1615 (1984).

6. J. L. Koenig and M. C. Agboatwalla, J. Macromol. Sci., Phys., B2, 391 (1968).

7. N. Vasanthan, N. S. Murthy, and R. G. Bray, Macromolecules, 31, 8433 (1998).

8. C. Ramesh, Macromolecules, 32, 3721 (1999).

9. F. Rybnikar and P. H. Geil, J. Appl. Polym. Sci., 46, 797 (1992).
10. H. Yoshida, G. Z. Zhang, T. Kitamura and T. Kawai, Thermal Analysis and Calorimetry, 64, 577 (2001).

11. H. Yoshida, Thermal Analysis and Calorimetry, 49, 101 (1997).

12. H. Yoshida, Thermal Analysis and Calorimetry, 57, 679 (1999).

13. G. Z. Zhang, T. Kitamura, H. Yoshida, and T. Kawai, Thermal Analysis and Calorimetry, 69, 939 (2002).

14. G. Z. Zhang, T. Kitamura, H. Yoshida and T. Kawai, NetsuSokutei., 29, 192 (2002).

15. H. Yoshida, R. Kinoshita, and Y. Teramoto, Thermochim. Acta, 264, 173 (1995).

16. G. Z. Zhang, T. Kitamura, H. Yoshida, and T. Kawai, Polym. Prepr. Jpn., 51, 639 (2002).

17. H. W. Starkweather, J. F. Whitney and D. R. Johnson, J. Polym. Sci., A1, 715 (1963).

18. P. J. Flory, J. Chem. Phys., 9, 660 (1941).

19. M. L. Huggins, J. Chem. Phys., 9, 440 (1941).

20. T. Nishi and T. T. Wang, Macromolecules, 8, 909 (1975). 